Daniels, I._Feeling at Home in Contemporary Japan: Space, Atmosphere and Intimacy.

\title{
Feeling at Home in Contemporary Japan: Space, Atmosphere and Intimacy
}

\begin{abstract}
This article explores what it means to feel at home in contemporary Japan. My objective is to expand on the existing social science literature about atmosphere that has paid ample attention to the staging of atmospheres in public spaces, but is still wanting for more detailed, qualitative studies about domestic atmospheres. A handful of studies focus on the intentionality of one inhabitant (usually the woman of the house) who selects and combines material culture in order to create a specific 'aesthetic' scheme. This is in line with other research about the home that emphasises front-stage concerns such as hospitality, status, and normativity. By focusing on 'back-stage' activities such as sleeping, eating and bathing that generate intimate sociality this article sets out to address this discrepancy. I will argue that in order to produce and sustain a 'homely' atmosphere inhabitants need to constantly balance the ideal of family solidarity with actual individual needs for autonomy and distance.
\end{abstract}

Key words: domestic space, intimacy, atmosphere, heat, Japan

\section{Introduction}

'[Japanese people] find it hard to be really at home with things that shine and glitter.' (Tanizaki 1977 [1933]: 10)

While writing this paper about homely atmospheres in Japan I frequently recalled my first stay in the country in the early 1990s when I shared an apartment with another Belgian student on the tenth floor of a block of flats in Yamada, a sleepy suburb in the north of Osaka. We were surprised to find that bright fluorescent ceiling lamps were the only light source in our new home and decided to buy some freestanding lamps to permeate every space with, what we considered, more soothing candescent light. Little did we know that this small modification would unleash a bizarre weekly ritual. The protagonist was our Japanese landlord who started his weekly inspection-visit marching from room to room switching on every ceiling light until the whole flat bathed in a bright neon glow. This domestic "turning on the lights" ceremony was always accompanied by some drawn-out ponderings about 'why Belgians are so dark' (kurai). At the time the comical connotations made between our dimly-lit environment and the moody personality of a whole nation seemed trivial, but when conducting fieldwork inside Japanese homes in the same area in 2003 and 2006, similar negative comments about 'dark' domestic spaces and the un-homely atmospheres they generated were repeatedly made. None of these Japanese people seemed to appreciate the 'beauty of feeble light', famously described by Tanizaki and every since associated in the 
Daniels, I._Feeling at Home in Contemporary Japan: Space, Atmosphere and Intimacy.

'West' with a unique Japanese sensibility that informs local understandings of hominess (Tanizaki 1977,18). By contrast, all were at home in neon 'lightscapes' (Bille and Sorenson 2007, 267) filled with 'things that shine and glitter'. During the 1930s, at the time of Tanizaki's writing, electrical illumination was rapidly replacing candles. Indeed, in Japan, as elsewhere, the development of light bulb technology (and electricity) is inseparable from the grand narrative about progressive modernity (Sneath 2009, 74-6) which, as Partner has shown in his study of post-war Japanese advertisements for electronic goods, resulted during the 1950s in the active promotion of 'the bright life' (akarui seikatsu) (Partner 1999, 149). In this context 'brightness' referred not only to modern homes lit with fluorescent light bulbs (ibid, 149) but also to the shiny commodities and the sunny character of the members of the 'modern', nuclear family, especially the newly emancipated housewife, inside (ibid, 153-56).

The idea of the 'bright life' and the pleasant domestic atmosphere associated with it still resonates today. However, in this article I will scrutinize this ideal by confronting it with the lived experience of atmosphere and its relationship to intimacy inside real homes. I will draw on one year of fieldwork in 2003 conducted inside thirty urban homes in the Kansai region 1 and a visual project carried out in the same area in 2006. The larger aim of this research is to challenge widespread stereotypes about Japanese minimal aesthetics by revealing the messiness and contradictions of everyday domestic life (Daniels 2010).2 However, the focus in this article will be on backstage bodily activities such as co-sleeping and co-bathing that generate 'social heat' and cultivate strong feelings of family solidarity and security. I will show that the successful reproduction of this intimate sociality inside the home is constantly threatened by and contingent on the realization of individual desires for relaxation and freedom, and argue that, unless a balance is achieved between dependence and autonomy, domestic atmospheres will be experienced as 'dark', 'cold' and conflict-laden. Overall, I hope to show that by paying attention to social, material and spatial constraints within a particular environment, we can start to unravel some of the complex entanglements of ideal, real and possible atmospheres and develop a more comprehensive understanding of how people experience atmospheres in practice in different cultural contexts.

As illustrated in the introduction to this special issue, the notion of 'atmosphere' has already been explored at great length by philosophers, urban planners and designers, but only in recent years has the concept received proper attention from social scientists (Anderson 2009, Thibaud 2011, Edensor 2012). Still, the majority of these studies tend to focus on the staging of atmosphere in the public sphere, and my research sets out to offer a novel perspective by investigating the everyday, lived experience of

\footnotetext{
1 In this urban area around Osaka twenty-five million people or twenty percent of the Japanese population live.

2 While living in Japan for six years I developed an extensive network of friends who acted as gatekeepers introducing me to five families with whom I lived with for at least one month each as well as fifteen homes that I visited regularly throughout the year. A further ten volunteers were recruited through public lectures about the project and notes posted on notice boards in public institutions. All participants considered themselves to belong to the 'mainstream', a concept that assumes inclusion instead of exclusiveness associated with class.
} 
Daniels, I._Feeling at Home in Contemporary Japan: Space, Atmosphere and Intimacy.

atmosphere inside the home. In the past twenty-five years growing numbers of anthropologists, influenced by the feminist critique about the natural body, the phenomenological re-thinking of rituals, and a more general dissatisfaction with both logo-centric and ocular-centric approaches, have engaged in the empirical and theoretical study of lived experience. Whilst theories of embodiment (Csordas 1994), that argue that people experience the world with both their minds and bodies, have become well-established, it is only in the last decade that attention has turned to the relationship between embodied knowing, perception and space. Both the anthropological research about the movement of sensate, perceiving bodies in particular environments (Ingold 2000, 2007), and the realisation that things, people and places are not finite entities but "constellations of processes" (Massey 2005) are important developments that this article builds on. However, I also aim to enhance these debates by arguing that a focus on the concept of atmosphere offers a unique opportunity to examine the complex affective, often fluid relationships between people, things and environments without prioritising human intentionality (Anderson 2009,80 ). This is particularly pertinent with regards to domestic atmospheres because, as I will demonstrate next, most previous studies have given undue importance to the role of housewives, portrayed as 'aesthetic workers' (Böhme 1993, 122), who draw on a complex set of aesthetic skills and knowledge to arrange a selection of objects (including lamps) in order to produce a 'homely' feeling. 3

\section{Methodology: Staging versus Experiencing Home-like Atmospheres?}

Qualitative research about domestic atmospheres remains scarce and the focus tends to be on the staging of ideal domestic atmospheres in the US and Northern Europe described with adjectives such as informal, cozy, and relaxed as opposed to the un-homely (generally linked with the public and commercial sphere) defined as formal, cold, and modern. Thus, in her classic study inside working class homes in 1970s Bergen, Gullestadt, for example, shows that 'a good Norwegian home has to be cosy and homely and warm. ... Cosiness is achieved by an abundance of furniture, small lamps, green plants and ornamental pieces...' (Gullestadt 1984, 87). In a more recent ethnography also set inside urban Norwegian homes the Irish anthropologist Pauline Garvey zooms in on the specific role of candescent illumination in producing outward expressions of normative homeliness (Garvey 2005, 168). Similarly, a Dutch study shows how elderly residents in Amsterdam create aesthetic arrangements of plants, porcelain figures, and vases on windowsills to express domestic cosiness or "gezelligheid" to passers-by (Van der Horst and Messing 2006), but it also establish hominess as an exclusive category because cosy Dutch homes are being contrasted with immigrant homes with closed curtains.

More recently, Olesen (2010) has explored how white, middle-class women in the US use ethnic

\footnotetext{
3 These practices form part of what Böhme has called 'production aesthetics' as opposed to 'perception aesthetics' (Aarhus March 2012). Elsewhere, I have shown how Japanese housewives also draw on a complex knowledge of the seasons in order to create intricate domestic displays (Daniels 2009).
} 
Daniels, I._Feeling at Home in Contemporary Japan: Space, Atmosphere and Intimacy.

objects to create sensuous domestic interiors. However, she argues that the compelling effect of interiors cannot be 'pinpointed as emanating from the furniture, decorative objects or built structures' alone and that the 'feel' of home is foremost grounded in sociality and solidarity (Olesen 2010, 32). Although ultimately Olesen fails to elucidate how domestic spaces are in practice 'continuously animated by social life', the suggested shift in focus from ideal aesthetics to lived experience is significant and it also underpins this article. To my knowledge, only two studies take domestic sociality as their starting point and both analyse the Danish concept of hygge characterised by activities such as 'being with good friends or with one's family or partner, having fun in an easy-going yet not overly exciting way (not a party, as such), talking and telling jokes in a relaxed manner, or perhaps watching a movie together or playing a board game' (Linnet 2011, 22-23). However, whereas Linnet reveals very little about how Danes negotiate hygge inside their homes, Bille's article in this special issue, that focuses on the role of lighting technology in the production of hygge, addresses this problem by showing that Danish people also desire a degree of detachment while being part of a larger social whole, a point I will return to later.

This said, most studies link domestic atmospheres with normative forms of sociability which brings to mind Simmel's famous discussion about 'Geselligkeit' (1949) that he defines as a 'playful mode of the social' that values 'correct form' thereby creating 'an ideal world of equal participants' in which 'the pleasure of the individual is always contingent upon the joy of others'. In a much-cited essay about style he further singles out the dining-room as the domestic space where this "cozy togetherness" (Gesellige Zusammernsein) is enacted; it is supposed to favour relaxation, the descent from the surging excitements of the day into a broader comfort shared with others' (Simmel 1991, 68). However, Simmel also suggests that these ideal concepts of sociability whether called coziness, gezelligheid or hygge can easily disintegrate if they 'get entangled with real life' (Simmel 1949, 258), and this entanglement is the focus of my inquiry.

The scarcity of empirical research about how domestic atmospheres are experienced and felt is, in my view, a direct consequence of the methodologies commonly employed to study the home. Most researchers only manage to gain access to the front areas of the home; frequently spaces associated with guests and hospitality, and therefore generally expressive of status and normativity. Limited access has also resulted in interviews being the main method to gather information. I am not arguing against the use of this technique per se, but it is problematic if only one inhabitant, generally the women of the house, is asked to narrate her (ideal) version of family life or in our case her aesthetic strategies for staging a homely atmosphere. Indeed, the only English-language publication about hominess that, to my knowledge, attempts to examine the multiple complex relationships inside lived-in homes is a more than twenty-five years old Dutch study that is based on interviews (Pennartz 1986). However, because the author allowed all those living under the same roof to voice their understanding of what it means to feel at 
Daniels, I._Feeling at Home in Contemporary Japan: Space, Atmosphere and Intimacy.

home contradictory understandings, ranging from 'communicating with one another' to 'being free to do what one wants', emerged. These findings hint at atmospheric tensions caused by the discrepancy between the social needs of the family group and the desires of the individuals within, an issue, that we will see below, is also at the heart of the success production of Japanese homely atmospheres.

The analysis of visual data, especially architectural plans of houses, is another widespread method employed to study the home. However, as anthropologist Christine Helliwell (1996) has argued in her seminal study of lived experience inside Dayak longhouses in Borneo, these kinds of visualisations tend to depict domestic spaces as orderly entities with doors, walls and other demarcations considered to represent solid boundaries. By contrast, her fieldwork shows that sound and light may easily permeate 'flimsy walls' and thus play a crucial role in fostering domestic sociality and a more general sense of community. Returning to the Japanese context, Ozaki and Rees Lewis (2006) offer an example of a study based on a combination of interviews and house plans that places undue emphasis on the impermeable nature of the inside-outside (uchi-soto) spatial and social domestic demarcations (Ozaki and Rees Lewis 2006). Thus, the step located inside the entrance hall that makes Japanese people remove their shoes before proceeding up into the home is said to function as a clear boundary between inside and outside space. However, only while observing everyday domestic activities in the entrance hall such as receiving postal deliveries, doing the laundry or putting out garbage may the liminality of this space, and more generally the fluidity of outside-inside boundaries be revealed (Daniels 2008).

In the next section, I will draw on well-tested methods such as the analysis of advertisements for new homes and interviews to establish the correlation between 'bright' atmospheres and Japanese ideals of togetherness that can be traced back to novel ideas about domesticity and the modern self that spread after WW2. By contrast, section 4 and 5 will primarily draw on observational data from my ethnography to demonstrate how in practice those living under the same roof enact a range of bodily practices that, assisted by a range of technologies, generate an all-encompassing heat. This 'warm' atmosphere yields connectivity and feelings of belonging without infringing on individual needs for detachment and withdrawal from social demands.

\section{The Bright Life: Family Togetherness, Sofas and Dining tables [INSERT FIGURE 1 HERE]}

As we have seen above, advertisements from the 1950s made direct links between brightly-lit domestic spaces filled with shiny commodities and the sunny, sociable character of its inhabitants. My analysis of advertisements for new homes received through the post in five of the homes studied reveals that in 2003 Japanese discourses about hominess focus less on illumination or domestic appliances that have become part of the taken-for-granted fabric of everyday life. Instead, the emphasis is on the layout of the 
Daniels, I._Feeling at Home in Contemporary Japan: Space, Atmosphere and Intimacy.

rooms and large pieces of furniture places inside that is thought to enable harmonious family togetherness and by extension a 'bright' atmosphere. Figure 1 shows a typical advertisement for a two-storied detached house with four interior spaces that are at the base of the conceptualisation of the ideal post-war Japanese home. They are introduced as follows, starting clockwise from the top right: (1) The dining-kitchen area: 'Of course we can install a popular front facing kitchen system which enables you to talk with your family while preparing meals', (2) The children's room: 'One would like to give one's children a room where they can study in peace', (3) The master bedroom: 'Anyone would like a bedroom just like this to relieve the fatigue of the day', (4) The living room: 'Why not try to gather the whole family in the living room to exchange opinions?' The dining-kitchen with adjacent living room also called the living-dining-kitchen area or LDK (the English abbreviation is also used in Japanese) is envisioned as a communal, social space where family members socialise while cooking and sharing meals, exchanging opinions or playing board games. Although stress is placed on togetherness, some allowance has also been made for the specific needs of individuals as ideally a private bedroom should be provided for the parents and one for each child. The expectation is that the former will enable the couple to relax together, while the latter will allow children to study independently in a calm atmosphere. This understanding of the ideal home is informed by the ideology of 'the happy family together', in turn the outcome of a series of complex historical processes that others have discussed in much detail (Sand 2003), but that I can only summarise very briefly here.

At the end of the nineteenth century the Meiji government (1868-1912) aspired to modernise Japan along western lines by replacing the patriarchal family unit (ie) grounded in Confucianist ideals of filial piety with a new type of domesticity based on the nuclear family and 'western' ideals such as conjugal love and the autonomous self. A key objective was the re-designing of the Japanese dwelling by shifting the focus from guest-centred to family-centred and from floor-based to chair-based living. During the 1920s a number of innovative floor plans were introduced that challenged previous layouts that reserved the larger, sunnier rooms for guests, while family-based activities took place in the darker areas in the back. These new homes called Cultural Houses had a family-centred dining-kitchen accessible through a central corridor, but this communal space, often with an adjacent living room, and the new type of domestic living associated with it, only spread among the masses during the 1960s with the development of suburban housing blocks (danchi), built in concrete and four or five stories high, that were funded by the government. Today the LDK (living-dining-kitchen) layout is standard, whether in detached houses or apartments, in rural or urban areas, and in 2003 all the participants in my study lived in homes with a central space with a number of bedrooms connected by corridors or stairs, and a private bath.

Large pieces of furniture such as sofas, dining tables and double beds alleged to be vital for enacting family solidarity were placed inside these new domestic spaces. Still, the idea that the whole family meets, 
Daniels, I._Feeling at Home in Contemporary Japan: Space, Atmosphere and Intimacy.

talks, plays, and entertains guests on an equal basis while in a communal area never caught on in Japan (Miyawaki 1998, 26-28). During my fieldwork sofas were prevalent but they were used either as a comfortable backrest while sitting on the floor or for stretching one's legs on while taking a nap. This latter use was particularly popular with men, who do not have their own private space for relaxation, but most women made negative associations between sofas and this kind of (male) domestic indolence. A good example was thirty-seven years old Mrs Matsui in Nara who joked that she insisted on buying a two instead of a three-seater sofa because it would preclude her husband from lying down for a nap. Similarly, many other married women used humour to channel their annoyance with the unequal division of domestic labour, thereby temporary suspending the social order and revealing the tensions between their own needs and the expectations of the larger group (Daniels 2010, 125-6). Helzfeld (1997) offers valuable insights, be it in the context of nationalism, about the relationship between humour and intimacy. He argues that because humour exposes the tension between the denial and recognition of certain truths, it generates 'cultural intimacy' essential for the successful re-production of national sentiments. I argue, similarly, that banter about the use of sofas that I witnessed inside many Japanese homes negates tensions between the genders and plays a pivotal role in the production of 'domestic intimacy' that nourishes the family group and assists in creating a feel of home.

In the homes studied the western-style dining table with chairs4, rather than the sofa set, was associated with family togetherness. Still, during my ethnography it became clear that the ubiquity of dining tables might be misleading because busy work and study schedules meant that family members ate at different times. It was common for housewives to either eat alone or with small children before warming up meals when their husbands, school going children or working adult children arrived home. Some families managed to have dinner together, at least a few times a week, but conversation was often kept to a minimum and some kept the TV on throughout. Moreover, the mother was frequently busy preparing and serving food while the others ate. Exceptions were the Kagemoris in Osaka who cooked and enjoyed their meals together, and the Takahashis in Nara who shared cooking responsibilities among the three adult females in the households. Finally, the dining table is often the only large flat surface in the house and it has therefore become associated with a number of activities unrelated to food preparation and consumption. Ideally children should be given a separate room to study in, but in practice the dining table is a popular spot for doing homework, while many adults also utilize it as a workspace (laptops have become a common feature). Table tops also double as extra storage space for an eclectic mix of everyday objects such as piles of mail, newspapers and magazines, containers for sauces, boxes with tissues papers, nail varnish, and appliances such as rice cookers or 'hot-pots' for heating water.

4 This table became widespread during the 1960s. Its predecessor was a low, wooden table called chabudai, that encouraged families to eat together on an equal basis and replaced individual meal trays in use until the end of the nineteenth century (Koizumi 2002, 155). 
Daniels, I._Feeling at Home in Contemporary Japan: Space, Atmosphere and Intimacy.

\section{Bodily Intimacy and the Choreography of Groupism}

Even if the family group does not spend much time socialising on sofas or at dining tables, family togetherness can also be achieved in other ways, and my research shows that bodily activities such as co-sleeping and co-bathing plays a key role in the production of intimate family sociality. The standardisation of the LDK layout in post-war Japan meant that most homes had at least one extra private room that, as the advertisement above illustrates (figure 1), should ideally be turned into a bedroom (with a double bed) for parents but actually it was frequently used as children's study room. Until the 1960s it was common for the family group to sleep together in one or more Japanese-style rooms. Adults would each sleep on a separate futon, while small children would share one with their parents or grandparents. Sleeping on futons on the floor (instead of in beds) facilitates co-sleeping because the mats can be spread out close to each other and a child can easily (consciously or unconsciously) roll from one onto the other. As Lebra poignantly put it: 'he may go to sleep in his mother's bed and wake up in his father's' (Lebra 1976, 141). In 2003 beds were prevalent, although double beds remained a rarity, but many participants also continued to sleep on futons. Sleeping arrangements of couples differed considerably, but, once children were born, most slept separately, often in different rooms. By contrast, parent-child co-sleeping was widespread. Indeed, all the children in my sample slept with either both or one of their parents until they started elementary school, and sometimes this practice even carried on until children reached puberty.

In his ethnography of a Japanese childcare centre in Kyoto, the anthropologist Eyal Ben-Ari also emphasises the importance of co-sleeping in producing a sense of communal and personal comfort and security, showing that it is through sleeping together with others and experiencing each others body warmth, a behaviour learned at home, that pre-school children 'embody in themselves the bonds and the sentiments of solidarity and intimacy of the peer group' (Ben-Ari 1997, 42-3). In a more recent ethnography conducted in a comparable setting in North-East Japan, Tahhan, a Japanese Studies specialist, similarly, argues that co-sleeping blurs the boundaries between bodies, between subjects and objects, and it is this 'state of ecological connectedness' (Tahhan 2008, 41) that makes intimacy and security possible. Both researchers point out that the soothing effects of co-sleeping are first experienced in the home, and my study corroborates the continuous importance of co-sleeping between parent (primarily the mother) and child in creating not only a sense of personal wellbeing but also family solidarity. The fact that affectionate ties are formed outside the romantic relationship between two individuals also indicates that in some cultural context intimacy may be disconnected from privacy.

Since the 1970s the intimate connection between a mother and her child produced through skin-to-skin contact has been discussed in Japanese cultural psychology literature as well as popular discourses by using the term "skinship" (sukinshippu). The anthropologist Takie Lebra defines it as 'not only physical 
Daniels, I._Feeling at Home in Contemporary Japan: Space, Atmosphere and Intimacy.

closeness but actual body contact between mother and child', citing examples such as breast-feeding and transporting babies on the back papoose-style (onbu), but also, and more interesting for our discussion, co-sleeping and co-bathing (Lebra 1976,138-141). More recently the Israeli anthropologist Ivry has argued that this mother-child bond already develops during pregnancy and that it, for example, causes older children to conceptualise their mother's body as an environment that they are nested in (Ivry 2010, 95-6). Lebra mentions 'skinship' within a larger discussion about Japanese intimate interactions, that are, in her view, 'outwardly and inwardly' (ibid. 115) expressions of unity. The outward articulation of intimacy is characterized by 'doing pleasurable things together' stressing the importance of physical proximity and the role of play. Intimacy is also communicated inwardly through 'silent communication, ishin denshin ("heart-to-heart communication") and mutual "vibrations", reading subtle signs and signals and the intuitive grasp of each other's feelings' (ibid. 115).

Like Lebra, many other anthropologists of Japan have emphasized that 'social unity is activated by situations rather than social relationships' (Lebra 1976, 116). Brian Moeran, for example, argues that:

Japanese are very aware of the ways in which each frame affects their social behaviour. They know instinctively where to take up a position in a room full of people, what bodily posture to adapt, what level of language to use when talking to others and what kind of things may be said when. ... they consciously mould both time and space to fit in with the performance of these frames - in the office, in meetings, at school, during formal drinking parties... . (Moeran 2005, 6)

These ideas about the importance of the setting, that highlight the necessity to (consciously) adapt to as well as (unselfconsciously) tune into to the feelings of others, resonate with my own fieldwork because my queries about 'atmosphere' (funiki) induced lengthy conversations about the subtle (mental and bodily) skills involved in creating smooth 'human relations' (ningen kankei) within a particular environment. 'Harmony' (chôwa) was repeatedly mentioned in this context because many considered atmospheres to turn lighter (akarui) or more pleasant as the setting became more harmonious.5 Funiki literally refers to the earth's atmosphere or an 'encompassing misty (fun) environment' (shûi) filled with 'air' (kûkí), but in its everyday usage the term expresses 'a feeling or mood (kibun) that people associated with a particular setting', further explained as 'a framework for activities' (online Kojien Dictionary consulted March 10, 2012).

'Kûki wo yomu', literally 'reading the air' but generally translated as 'sensing or feeling the atmosphere'

5 Although 'harmony' has all too often been uncritically elevated to a unique trait of Japanese groupism, we should not underestimate its significance as a philosophical principle that is 'to be realized as people subordinate selfish goals to collective aims, and as they perceive their dependency on others' (Clammer 1995, 103). Individual relationships of trust are integral to Japanese social life but people are also aware that 'no one autonomously writes his own life' (ibid. 103). 
Daniels, I._Feeling at Home in Contemporary Japan: Space, Atmosphere and Intimacy.

is an idiom that consistently surfaced during my fieldwork.6 Mrs Kema, a single, cram school teacher in her mid-fifties, explained that 'to read the air' means that one is 'able to adapt to a certain setting', which she elucidated as follows:

When I was at kindergarten and our teacher would say: "what would you like to be when you grow up" and all the boys would say "fireman", "bus driver" and so forth, while the girls would answer "bus girl" [bus conductor], "a bride", etc.. And I, although I really wanted to say a scientist, because I knew that this answer would not fit that particular setting (sone ba), I also answered "bus girl".

The quote above shows that children learn about the importance of adapting to the setting and are socialised into the concept of the group at a very young age. Ben-Ari's study of Japanese childcare is again informative because he argues that the kindergarten is an important experiential setting in-between home and the outside world where children, on the basis of emotions and attitudes already learned at home, are taught the 'choreography of groupism' through intimacy with peers (Ben-Ari 1997, 73). In Japanese social science literature the ability to 'read the air' frequently appears referring to those not proficient in adapting to a particular setting. A recent article about university students unable (or unwilling?) to sense the atmosphere in a range of different social settings such as part-time jobs or sports clubs, for example, concludes that those who cannot read the air are self-centred; they choose to 'stress their own opinions and beliefs', instead of 'being in harmony with their environment' (Oishi 2011, 83-4).

How does this discussion about setting translate within the context of the home? Lebra claims that although the ideal 'tension-reducing' setting that facilitates intimate interaction should be one's home (recall Simmel about social play between equal partners), in practice chores get in the way of play, while status distance linked with age and sex is also common (ibid. 118).7 As I have shown above, in the homes I studied fathers, school-going children and working young adults (as well as increasing numbers of working mothers) were absent from the home for most of the day, and instances when all those living under the same roof 'spend time together' were few and far between. Moreover, while men tend to associate the home with relaxation, most women, who are often solely responsible for its smooth running, equate it with work. These observations are very much in line with Lebra's thinking, but where my research parts with hers is that, in my view, the home is also a place of experimentation where ideal social scripts are tested and questioned (Miller 2001). In the next section, I will explore how all inhabitants (parents, children - increasingly unmarried adult female children - and grandparents) engage in bodily activities that aim to balance the communication of unity with specific needs for relaxation of the individuals. My emphasis will be on a number of technologies that directly heat the body and assist in producing a soothing, encompassing 'warm' atmosphere associated with feeling at home.

\section{Windows and Warm Atmospheres}

During my ethnography many people talked at great length about the importance of 'reading the air' in public settings, often referring to the much-cited discourse about harmony and groupism discussed above.

\footnotetext{
6 'Research about Atmosphere' (kûki no kenkyû), a Japanese bestseller published in 1977 by the cultural commentator Yamamoto Shichihei, is embedded in the essentialist nihonjinron (discourses about the Japanese) literature, popular at the time, that depicts Japan as a unique society impenetrable by outsiders. Yamamoto argues that the distinctive Japanese understanding of 'atmosphere' is at the base of their group-based society, but he also critiques this concept for being directly responsible for the dangerous fundamentalism that led the nation into war.

7 Lebra (1976) goes on to propose that intimate relationships may actually flourish more easily in 'public' settings segregated from work. Examples are office parties or trips with school friends where in the "homelike atmosphere of a private room in a hotel, restaurant or teahouse' status boundaries are lifted, often with the help of 'the tension-reducing power of sake' (Lebra 1976, 118).
} 
Daniels, I._Feeling at Home in Contemporary Japan: Space, Atmosphere and Intimacy.

However, queries about what constituted a homely atmosphere were far less fruitful. As the editors of this special issue rightly point out in the introduction, atmospheres are 'vague' and they are therefore 'difficult to locate' and not easily put into words. Advertisements frequently depict a tatami room, adjacent to the dining-kitchen, where the whole family can relax. However, since the mid-1990s most homes have wooden flooring throughout and my observations suggest that feeling at home (kutsurôgu) is not so much linked with tatami mats but with removing shoes and sitting (but also sleeping) on the floor. The comfort experienced through this direct bodily contact with the ground also explains why it remains common to turn one corner of the LDK area into a space where one can sit around a low table on the floor.

An anthropologist will probably only during the initial phases of fieldwork detect a (cultural specific) homey feel, because over time she too will become 'attuned' to this phenomenon. Thus, I have become accustomed to shoe removal and sitting or sleeping on the floor, but, as I have indicated in the introduction, some (more intrusive) elements of Japanese hominess such as the pervasive neon glow remain alien. Most Europeans experience incandescent lighting as warm (see Bille in this issue), but the Japanese participants in my study, like my landlord many year ago, associated this kind of light with 'cold', un-homely atmospheres. A study about energy use in Norway and Japan from the 1990s (Wilhite et al., 1996) explains this phenomenon arguing that Japanese people are 'more interested in visibility than in mood'; the emphasis is on what is illuminated instead of the light itself (ibid. 800). Still, we might gain further insights into the Japanese proclivity for bright, fluorescent lights, often switched throughout the day, by paying attention to another domestic 'technology': the 'humble' window.

Although the ideal Japanese home depicted in figure 1 shows interior spaces saturated with light beaming in through large windows, in real, lived-in homes natural light is in short supply. Most windows are frosted while a great variety of covering devices are employed not only to protect the home against intruders and bad weather but also to block the gaze of neighbours, passers-by and inhabitants. In all the homes studied an array of curtains and blinds were hung on the inside of windows and the outside was shielded with wooden or metal shutters (figure 2). Moreover, security bars are attached to windows on the ground floor or facing streets, while in summer bamboo blinds offered extra protection against the sun (figure 3). In other words, fluorescent lights are constantly switched on to compensate for the unusually dark feel of domestic spaces even during the day [INSERT figure 2 and 3 HERE]

Windows (and their many material attachments) are devices that not only monitor the level of natural light permeating inside, but also control the circulation of (warm and cold) air. Interestingly, the architectural historian Watanabe has shown how innovations in Japanese window design have impacted on the development of heating technologies (Watanabe 2008, 53). He particularly emphasizes the introduction of the aluminium sash window (alumi sasshi)8 during the mid-1960s because it made 
Daniels, I._Feeling at Home in Contemporary Japan: Space, Atmosphere and Intimacy.

Japanese homes airtight, 9 keeping the cold winds as well as insects, mice and snakes outside. An advertisement from 1964 promoted these windows with the slogan: 'Lets enveloped ourselves in heat with these windows'. During the same period the danbô, an electrical heater hung up high against walls to heat up a whole room, arrived on the scene, followed in 1968 by the hybrid heating/airconditioning unit (danreibô) (ibid. 55).10 In 2003 the danreibô was present in most homes studied, but freestanding heating units that directly heat the body (especially legs) while sitting on the floor and encourage people to huddle closely together have remained extremely popular.

Many singled out the electrical kotatsu, first introduced in 1959, as a heating device associated with hominess. It consists of a low table with a heat source attached underneath that is covered with a square, quilted blanket. Both legs are placed into the cosy heat trapped underneath the table, while the blanket wrapped around the lower part of the body is shared with others seated in close proximity. Kotatsu are often used in combination with electrically heated or 'hot carpets' (hotto kaapetto), but in summer one can sit around the low table (without using the blanket) on cushions (zabuton) placed on top of a rug. Questions about the kotatsu generally elicitated nostalgic stories about childhood and powerful, past experiences of belonging and feeling at home. Mrs Kema, the single teacher in her fifties introduced above, answered my query about domestic 'spaces for relaxing' (kutsurôgu supeisu) as follows:

When I was little we sat around a 'hori kotatsu' [a kotatsu built into the floor] in winter. That was the setting (ba) of the family; and closeby, there would be a hibachi (charcoal brazier). I really love the hibachi. We would gather around it and relax. We would place a mesh on top and bake dried potatoes, pounded rice cakes (mochi) and so on.... Well, you know, today, it would probably be a room with a TV in it?

The quote above confirms how until fairly recently a variety of freestanding domestic heating sources were used to warm the body directly. Earlier in our discussion Mrs Kema also talked about the 'irori', a sunken fireplace cut in the middle of the floor that enabled family sociality, but that, like the charcoal brazier that she speaks so fondly off, is no longer part of everyday life. Her comment about television is also astute because TV's were often referred to in my conversations about 'feeling at home'. However, in this context people tended not to use the term kutsurôgu, but 'bôtto suru' or 'being lost in thought', a term with a strong connotation of individual wellbeing, best achieved while sitting on the floor staring at the box. Contrary to popular discourses that associate the TV primarily with passivity, alienation and isolation, the

spread to single dwellings during the 1970s (Watanabe 2008: 52-3).

9 As a result of growing numbers of people living in airtight spaces both in winter and summer (and air-conditioning untis becoming widespread) "sick house syndrome", a series of health problems (most frequently respiratory illnesses) cause by polluted indoor air, has increased dramatically.

10 Whilst in 1950 charcoal braziers were still widespread, they were rapidly replaced by a series of stoves whether they used gas (1952), electricity (1955) or petrol (1962) (Watanabe 2008: 55). 
Daniels, I._Feeling at Home in Contemporary Japan: Space, Atmosphere and Intimacy.

device also functions as an important facilitator for the enactment of togetherness while simultaneously enabling individuals to retain some distance. Indeed, watching TV, often while sitting on the floor and consuming food or drinks, allowed many participants in my study to both express solidarity by being in close proximity to others and lose one self in idle thoughts.

\section{Social Heat, Seasonality and Space}

I have shown above that Japanese people prefer to control the temperature of the body directly. The fact that most participants in my study changed not only their clothing and bedding but also appliances (heaters for fans) and other interior features (winter curtains for summer blinds; hot carpets for rugs) seasonally provides further proof. Another practice that warms the body and is thought to produce domestic sociality is the consumption of food. During my fieldwork the correlation between 'hot' foods, bodily heat and well-being was repeatedly brought to my attention. The time of the day but also the season when food is eaten is considered important. As a vegetarian I like to eat salads for dinner, but I was repeatedly berated for eating food that 'cools the body', especially at the end of the day. Similarly, many frowned upon my yearning for chilled drinks during the scorching summer months, instead accentuating the healthy benefits of hot beverages.11 For Mrs Kema pounded rice cakes are 'hot' comfort foods associated with hominess, but most Japanese consume these auspicious cakes en mass during the New Year's period, a time of regeneration and relaxation, when the majority of people will take at least a few days off work and some, fewer each year, will return to their rural family home (figure 4). As Charles Stafford has shown, drawing on Mauss' seminal work about the seasonality of Eskimo sociality, the intensity of social life (in China in his case) can only be sustained if it is alternated with (seasonal) periods of slowing down or detachment. However, unlike Mauss, he alleges that both exertion and recuperation are being constitutive of collective solidarities (Stafford 2000, 175-6). Stafford's research is particularly pertinent because he also stresses the role heating technologies play in the production of intimate sociality. The kang, a heated platform-bed found in North China, for example, facilitates various activities that produce social heat such as eating meals, playing cards, conceiving, giving birth to and minding children, and of course co-sleeping (ibid. 133-5). In the Japanese homes studied periods of exertion and relaxation also alternate and when most people also slow down during Obon in mid-August. This is the hottest time of the year, when ancestors are thought to return to their family home where they are enveloped by and partake in the social heat generated by their descendants. Thus, in Japan warm, homely atmospheres may also blur the boundaries between the dead and the living. [INSERT FIGURE 4 HERE]

11 I am unable to explore indigenous folk theories about body heat and health here, but in her comparative ethnography of pregnancy in Japan and Israel Ivry reveals how the Japanese doctors she worked with drew on East Asian medicine (kanpô) to propagate a similar discourse about the healthy effects of heating the body (ivry 2010, 95-6). 
Daniels, I._Feeling at Home in Contemporary Japan: Space, Atmosphere and Intimacy.

Finally, many participants associated feeling at home with bathing, another practice that warms the body directly. This is a daily ritual that happens in the evening before going to bed and continues throughout the year, also during the summer months. Like dining-kitchen and bedrooms, private bathrooms were an innovation introduced through the danchi apartments (Aoki 2001, 18-9). However, unlike the idealised social practices associated with the former two spaces, bathing was already widespread during the Tokugawa period (1600-1867). Only the elite possessed private bathtubs, but all strata of the population enjoyed public baths (sentô), which were - and in some urban neighbourhoods still are - popular places for socializing and relaxing (Morse 1886: 203). Indeed, in 2003 many people referred to going to a hot spring with family or friends as their favourite activity to 'unwind' (kutsurôgu). Domestic bathing was also considered relaxing, but unlike public baths or hot springs where adults of the same sex tend to bathe together, naked, in close proximity, in the home adult family members will take their daily bath in turn while small children bathe together with a parent or grandparent. 12 The body is repeatedly cleansed before stepping into the tub filled to the brim with hot water, kept at a constant temperature with heating technology and shared among family members. By immersing themselves daily in the same hot bath water those living under the same roof are intimately connected and a sense of belonging and skinship is nurtured.13

Most advertisements for baths directly target men assuming that they as breadwinners are particularly keen to enjoy a warm soothing bath at the end of the working day. However, today many married women juggle housework and taking care of children or the elderly with a part-time job, and they are therefore as eager as their husbands to want to relax in the bath, often the only private space where adults can escape social demands. Mrs Kuwahara epitomises this blurring of ideal gender roles; she is a part-time high school teacher, while her husband is a chemist. Both are in their mid-fifties and they live in a two-storied detached home in Itami City together with their two teenage daughters, Keiko and Yoshiko. Most days, Mrs Kuwahara will arrive home from work in the early afternoon to start her housework and prepare the evening meal served soon after Mr Kuwahara returns home at $6 \mathrm{pm}$. The family enjoys having dinner together at a large table in their dining-kitchen, but it is usually a quick affair, and by the time Mrs Kuwhara and her daughters are cleaning the table and tidying up, Mr Kuwahara will already be engrossed in work at his desk in his private study/bedroom. Soon Keiko and Yoshiko will also retire to their bedrooms to do homework or they might relax in a Japanese-style room adjacent to the dining-kitchen reading magazines, doing handiworks and watching TV. Mrs Kuwahara, on the other hand, will still have several hours of housework ahead of her. Around 10 pm Mr Kuwahara will take his bath and after he retreats upstairs the girls will take turns in the bathroom. Close to midnight, once the day's

\footnotetext{
12 In the past family members would take their bath in turns in accordance with their status, but this practice has been disrupted by the long working hours of the breadwinner and elderly people and small children tend bathe first.

13 The importance of bathing in the (re) production of the family group is also illustrated by the final ritual bathing of the deceased (yûkan) that close relatives continue to be (at least symbolically) involved in (Suzuki 2000,74-83).
} 
Daniels, I._Feeling at Home in Contemporary Japan: Space, Atmosphere and Intimacy.

laundry hangs out to dry, Mrs Kuwahara will finally bathe. It is not unusual for her to subsequently recline on the tatami mats in their Japanese-style room while watching TV (particularly if Sumo is on) or skimming through the newspaper scanning grocery discounts while sipping a 'cold' beer (in summer) and (for a few weeks in 2003 at least) gossiping with the 'in-house' anthropologist.

Being immersed in the hot bathwater or through soothing whole bodily contact with the ground, whether or not while eating or being engulfed by the emanating warmth of heating elements, those participating in my study experienced a certain 'depth of space'. This all-encompassing, spatial experience resembles the relational phenomenon that Tahhan (2008) describes in her ethnography inside Japanese day care centres. Indeed, she holds that the feeling of belonging experienced by pre-school children through physical touch can be extended to a more general 'sensuous experience of space that is all-encompassing and inclusive of more than just the body' (Tahhan 2008, 51). Tahhan draws on the Japanese philosopher Ichikawa Hiroshi, in turn influenced by Merleau-Ponty, who connects this 'at home' feeling (he also uses kutsurôgu, see Ichikawa 1993, 161) with the Japanese concept mi. Mi is often translated as "body", but Tahhan defines it as 'an infinite (all-encompasing, whole, not-contained) space that includes body, mind, heart (spirit) self, relationality and whole existence, including that which is attached to mi' (ibid, 41). These attachments may be garments but also futons or floors. Japanese domestic atmospheres may be conceptualised as infinite spatial phenomena, but my research also suggests that the relational quality of space is more effective in producing the intimate sociality that makes people feel at home when it is 'lubricated' by heat.

\section{Conclusion: Ideal, Real and Possible Atmospheres}

In this article I have argues that homely atmospheres emerge at the intersection where the ideal and the real coalesce in complicated ways. In the ideal post-war LDK home the family group is supposed to engage in pleasant, social activities in a well-lit communal space. However, in reality, in Japan, as elsewhere, relationships between the individual and the group are continuously contested, negotiated and created anew inside the home. Like the recent social science literature that holds that atmospheres are 'part of an overall movement that expresses and conditions the way we behave and act collectively' (Thibaud 2011, 207), my research in Japan shows that hominess is not locatable in separate (living or dead) individuals nor in specific items of material culture but that atmospheres are all-encompassing phenomena that guide people's collective activities. However, where my work differs is that I argue that the lived experience of intimate atmospheres is shaped within the dynamic interplay between involvement in and detachment from sociality. In Japan these atmospheric tensions are articulated through two sets of binary opposition; light versus dark and warm versus cold. The former is embedded in discourses about modernity that promote new 'bright' forms of domesticity and personhood, while the later is linked with the 
Daniels, I._Feeling at Home in Contemporary Japan: Space, Atmosphere and Intimacy.

actual experience of the 'warm' feel of home.

My ethnography elucidates that intimate forms of sociality, that do not necessary sacrifice individual yearnings for relaxation and escapism, may emerge within a warm, expansive heat, generated by bodies in close proximity and assisted by heating technologies (whether they produce warm air or water). This Japanese case study could thus be construed as an example of "idiorrhythmy", a term associated with ancient utopian monastic practices, but used by Barthes to describe the 'fantasy of living together' based on 'balancing individual and communal rhythms of life' (Barthes 2013, 6-9). Throughout this article I have demonstrated just how difficult and complex a balancing act this is, but individual and communal rhythms are more in tune at certain times of the year, such as the New Year and Obon, or specific moments of the day; especially in the evening after bathing. During these periods of relaxation a Japanese individual may engage in family-oriented activities sharing a hot meal together at the dining table or enjoying cup of tea huddled under the kotatsu, but activities such as soaking in the bathtub or lying on the floor with a cold beer in front of the TV in the summer heat are equally important for the well being of the family and the (re)production of a home-like atmosphere.

\section{References}

Anderson, Ben. 2009. Affective Atmospheres. Emotion, Space and Society 2: 77-81.

Aoki, Toshiya. 2001. Danchi 2DK no kurashi: saigen - showa 30 nendai (Life in a 2DK Danchi: The re-appearance of the 1950's). Tokyo: Kawade shobo.

Barthes, Roland. 2013 [2002]. How to live together: Novelistic simulations of some everyday space. New York: Columbia University Press.

Ben-Ari, Eyal. 1997. Body Projects in Japanese Childcare. Surrey: Curzon Press.

Bille, Mikkel and Tim, Sorensen. 2007. An Anthropology of Luminosity: The Agency of Light. Journal of Material Culture 12: 263-284.

Böhme, Gert. 1993. Atmosphere as the fundamental concept of a new aesthetics. Thesis Eleven 36: 113-126.

Clammer, John. 1995. Difference and Modernity. London: Kegan Paul International.

Csordas, Thomas. 1994. Embodiment and Experience. Cambridge University Press.

Daniels, Inge. 2008. Japanese Homes Inside Out. Home Cultures 5(2): 115-40.

Daniels, Inge. 2009. The Commercial and Domestic Rhythms of Japanese Consumption. Ed. Elizabeth Shove and Frank Trentmann, and Rick Wilk. Time, Consumption and Everyday Life: New agendas and directions. Oxford: Berg.

Daniels, Inge. 2010. The Japanese House: Material Culture in the Modern Home. Oxford: Berg.

Doi, Takeo. 1973. The Anatomy of Dependence. New York: Harper § Row. 
Daniels, I._Feeling at Home in Contemporary Japan: Space, Atmosphere and Intimacy.

Edensor, Tim. 2012. Illuminated atmospheres. Environment and Planning D 30: 1103-1122.

Garvey, Pauline. 2005. Domestic Boundaries: Privacy, visibility, and the Norwegian window. Journal of Material Culture 7: 157-76.

Goffman, Ervin. 1974. Frame Analysis: An Essay on the Organisation of Experience. London: Penguin.

Gullestadt, Marianne. 1984. Kitchen Table Society. Oslo: Universitetsforlaget.

Helliwell, Christine. 1996. Space and sociality in a Dayak Longhouse. In M. Jackson (ed.) Things as they are New directions in Phenomenological Anthropology. Bloomington: Indiana University Press.

Herzfeld, Michael. 2005. Cultural Intimacy: Social Poetics and the Nation-State. London: Routledge.

Ichikawa, Hiroshi. 1993. Mi no Kôzô (Bodily Structures). Tokyo: Kodansha.

Ingold, Tim. 2000. The Perception of the Environment. Oxford: Routledge.

Ingold, Tim. 2007. Lines: A brief history. London: Routledge.

Ivry, Tipsy. 2010. Embodying Culture: Pregnancy in Japan and Israel. London: Rutgers University.

Koizumi, Kazuko. 2002. Chabudai no showa (The low dining table during the Showa period). Tokyo:

Kawade Shobo.

Lebra, Takie. 1976. Japanese Patterns of Behavior. Honolulu: University of Hawai'i Press.

Linnet, Jeppe. 2011. Money Can't Buy Me Hygge. Social Analysis 55 (2): 21- 44.

Massey, Doreen. 2005. For Space, London: Sage.

Miller, D. (ed.) 2001. Home Possessions, Oxford: Berg.

Miyawaki, M. 1998. Miyawaki Mayumi no ii ie no hon (Miyawaki Mayumi's Book about Good Houses),

Tokyo: PHP kenkyusho.

Moeran, Brian. 2005. The Business of Ethnography. Oxford: Berg.

Morse, E. 1886. Japanese Homes and Their Surroundings. London: Sampson Low.

Nakane, Chie. 1967. Tate shakai no ningen kankei (Japanese Society). Tokyo: Kodansha.

Oishi, Chitose. 2011. Feel the Atmosphere in Sports Club Situations and Daily Relationships with Friends.

Tokyo Women's College of Physical Education and Tokyo Women's Junior College of Physical Education Journal 46: 75-85

Olesen, Bodil. 2010. Ethnic objects in domestic interiors: space, atmosphere and the making of home. Home Cultures 7 (1): 25-42.

Ozaki, Ritsuko and John Rees Lewis. 2006. Boundaries and the Meaning of Space: A Study of Japanese House Plan. Environment and Planning D, 24 (1): 91-104.

Partner, Simon. 1999. Assembled in Japan: Electrical Goods and the Making of the Japanese Consumer. University of California Press.

Pennartz, Paul. 1986. Atmosphere at Home: A qualitative approach. Journal of Environmental Psychology 6: 135-153. 
Daniels, I._Feeling at Home in Contemporary Japan: Space, Atmosphere and Intimacy.

Sneath, David. 2009. Reading the signs by Lenin's light: development, divination and metonymic fields in Mongolia. Ethnos 74(1): 72-90.

Tanizaki, Junichiro. 1977. In Praise of Shadows. New Haven: Leete's Island Books

Thibaud, Jean-Paul. 2011. The Sensory Fabric of Urban Ambiances. Senses and Society 6 (2): 203-215.

Tahhan, Diana. 2008. Depth and Space in Sleep: Intimacy, Touch and the Body in Japanese Co-sleeping Rituals. Body \& Society 14 (4): 37-56.

Sand, Jordan. 2003. House and Home in Modern Japan. Cambridge, MA, Harvard University Press.

Simmel, Georg. 1949 [1910]. The Sociology of Sociability (Soziologie der Geselligkeit). American Journal of Sociology: 254-61.

Simmel, Georg.1991 [1908]. The Problem of Style. Theory, Culture and Society 8: 63-71.

Stafford, Charles. 2000. Separation and Reunion in Modern China. Cambridge: Cambridge University Press.

Suzuki, Hikaru. 2000. The Price of Death: The Funerary Industry in Contemporary Japan. Stanford: Stanford University Press.

Van der Horst, Hilje, and Jacqueline Messing. 2006. Its not Dutch to close the curtains. Home Cultures 3: 21-37.

Wilhite, Harold, Hidetoshi Nakagami, Takashi Masuda, Yukiko Yamada. 1996. A cross-cultural analysis of household energy use behaviour in Japan and Norway. Energy Policy 24 (9): 795-803.

Yamamoto, Shichihei. 1977. Kûki no kenkyû (Research about atmospheres). Tokyo: bungeishunju.

Watanabe, Mitsuo. 2008. Mado wo hirakenakunatta nihojin. Sumiakata no henka 60 nen. (The Japanese who stopped opening their windows - 60 years of changes to the dwelling). Tokyo: Nobunkyo. 